\title{
Establishing Critical Thinking Course for High School Students in China: A Literature Review in Pedagogy Field
}

\author{
Yuhao Huang ${ }^{*}$ \\ Ningxia University, China
}

\begin{abstract}
This review synthesizes researches on students' critical thinking (CT) abilities from school education. It examines factors related to the importance of CT skills to students worldwide, identifies the current statues of the CT skills of students in China, and describes practical principles in real teaching scenarios. A total of 17 studies met the inclusion criteria. The key findings from the review are (a) massive worldwide investigations have offered various proposals and emphasized the significance of CT throughout the history; (b) Chinese students still generally undertake the gloomy image of CT capabilities; (c) an integration of a CT course to the curricula in a regular basis and a design of inquiry-based lesson plan need to be adopted in schools. The finding indicates that setting a CT course in high school can potentially assist students and schools to achieve the goals. For future research, a new curriculum for Chinese high schools to improve Chinese students' CT abilities needs to be determined.
\end{abstract}

Keywords: Critical thinking, China, high school, students

\section{Introduction}

\section{Background}

Critical Thinking (CT) as a philosophical topic is now wildly discussed around the world. Such a thinking pattern inspiring creativity of people matches the trend that innovation is the leading role in development $(\mathrm{Xi}$, 2018). Moreover, CT not only brings significant benefits from the Socrates' period, in which a known critical thinking teaching strategy named "Socratic Questioning" prevailed until now, but also shows potentials to boost human development. In pedagogy field, previous studies have conducted investigations about it from different views, some discussing students' CT competences through observing how students behave in various settings (Çakır, Cengiz, 2016; MirshahJafari, Sharif, Asgari, \& Omidi, 2018; Pei, Zheng, Zhang, Liu, 2017; Zhou, 2015), while some exploring the origin of CT and how it goes into effect in education field (Lin, 2016; Willingham, 2008; Zhu, 2015; Liu, He, Li, 2015; Mehta and Al-Mahrooqi, 2015).

Critical Thinking is the summation of objective, innovative, reflective, analytic, open-minded, interpretative, and evaluative thinking skills, which is impelled by rationality and multiple perspectives (Dong, 2013). It is a typical thinking mode receiving high attention in education filed. People teach this thinking mode to others in different ways, such as analyzing issues, sharing experience, explaining its philosophical meaning, and etc.Text format

China, an influential developing country, has realized the importance of CT. In the report of the work of the government in 2017, Li (2017) said China had strengthened the importance of innovation and were spurring the rapid development of new growth drivers. In recent years, China has exhibited its rapid change and visible progress to the world and becomes a pioneer in many research fields nowadays. However, in terms of some results from involved academic papers, the whole conditions of Chinese students' critical thinking capabilities are not optimistic. Under Chinese special systematical education, some issues occurring cannot be handled by western majority pedagogy theories, left there to arouse more conflicts. How to improve the next generations' creativity is an inevitable knot that the nation needs to consider carefully if the country wants to flourish 
constantly. Therefore, Chinese government needs to find out a common zone for both its own national conditions and CT teaching, which needs proper reformations.

High school is the critical transition period for Chinese students. Students need to handle various problems from 6 to 9 subjects, may lead to a study life with great burden. Their schedules are full with the preparation for the entrance examination of the university (Gaokao). Scores is nearly the only focus for Chinese students among High school's setting criteria, making CT skills or CT education shaded. "Studying machine" in some way should be called "intimating robot" which is not further beneficial to the university education and higher education in China. It means that the lack of critical thinking capabilities from high school, sometimes will impact the genius-fostering plan in China and decrease its ability of competition in the whole world. Moreover, the burden in high school is compulsory while the encumbrance in university is not. Students with free choice from a high-pressured environment often cannot study as hard as before, which also does harm to the CT competence of Chinese students.

As a junior student in undergraduate period majoring in English Education in Double First Class university, which means the universities famous for its overall behavior or one special major after national assessment in China in terms of the education policy (readers can regard the university with this title Double First Class in China a quite famous university). The author has learned some pedagogy theories and experienced teaching practice including pseudo teaching and real one. When reflecting Chinese students learning problems in current period, the direct feelings for the author is the lack of high CT competence of schoolmates around. After acquiring some knowledge in CT and CT in China, the author focuses on the period of high school, an important but critical and transition time for students in China. Seeking a proper way to help Chinese students to improve their CT capabilities become a motivation to this literature review.

\section{Purpose of the Study}

This paper summarizes 17 publications' essential points or themes about CT itself and conditions of acquisition of CT skills or competence in the whole world. During this process, it gets some related information to help readers reflect the problems that Chinese high school students face more clearly. It aims to evaluate the possibility for Chinese policies makers to establish a separate CT course to improve Chinese students' CT capabilities. In doing so, the paper weighs three themes: First, it shows the importance of critical thinking skills to students. Second, it exhibits the situations of Chinese students' critical thinking skills. Third, it displays some scenarios about how to teach critical thinking skills in real classrooms. Based on the key findings, it also manifests its own ideas and presents recommendations towards the current matters from three perspectives: policies makers, teachers and scholars or researchers.

\section{Methods}

At the primary stage, this passage chose Educational Resources Information Center (ERIC) as my database. Compared to other Anglophone websites, it was much easier for me to operate. For improving my sufficiency, I firstly browsed the Advanced Search Tips. It offered several ways to create more specific searches and other practical information. I did not use the options "peer reviewed only" and "full text available in ERIC" to limit my searching scope because the advanced search was precise and practical. I set the criteria of the date of publications I wanted to look through from 2014 to 2018. Because these four years included my main time in high school and freshman period in university when I gradually understood CT and learned deeper of it. Then I put Critical Thinking, China, High School into the searching blank due to my own topic. ERIC provided me a total number of 20,828 articles, which was too much for operating. So I used quotes to group words into specific phrases like "Critical Thinking" to decrease the quantity. Then I used "Critical Thinking", "China" and "High School" as my second-time searching key words. However, it just showed 8 results, only one involved them became one of my references, which was written by Siyi Lu and Michael Singh, discussing reasons of Chinese 
students' lack of critical thinking and gave a new idea about that. To see other possible consequence, I eliminated "High School" for extending results, getting 26 passages. And I found some related workings after scanning the whole list. When examining some papers, I found lots of authors use item "Critical Thinking Skill”. Therefore, I replaced "Critical Thinking” with "Critical Thinking Skill” Although that discussions about students' critical thinking current conditions and future expectations in different countries could be parts of my literature review, my focus was picking references about high school students. Therefore, I changed my key words to "Critical Thinking Skill" and "High School" to see the outcome, and the result was 439 in total. To control the number in a proper scope, I clicked the Full text available on ERIC. But there were still 177 results. Furthermore, I found some papers discussing mathematics, technology and some unrelated topics. Therefore, I added "Education", more general than pedagogy, to my key words. Then I got 22 publications, many of them matching my expectations and becoming parts of my references.

Besides, I used Open Access Library (OALib) as my database. Unlike ERIC, it was not an all-English website. Although it had a huge amount of resources, it could just provide a simple, extensive searching service, which easily brought substantial unnecessary outcomes. Firstly, I chose "Critical Thinking" and "China" as my key words, and both of them referred to the all field. It provided me 1275 articles. Here I still used the time criteria when using ERIC, limiting the date from 2014 to 2018. It decreased the number to 113. Scanning all of the 113 articles' titles, I found that the amount of unrelated publications cover a big part. So I changed my key words and their fields. Secondly, I replaced Critical Thinking's field to Items, High School to China and its field to Items. After such procedure, I got 6 passages that I could use.

Additionally, some used references were against the time discipline because while I studied the selected publications from the two databases, they were also one of the references in some of them. These papers were really useful so I specially chose them.

\section{Key Findings}

\section{The importance of critical thinking skills to students}

Critical thinking is highly focused in pedagogy for its essential importance in shaping a student's characteristics and learning competence. Tapung, Maryani, Supriatna (2018) did quantitative and qualitative analysis through interviews of junior high school students and tests on the assessment of their learning outcomes in Manggarai. They found that the level of understanding of the information and students' active involvement increase markedly due to the critical thinking exercise in Emancipatory Learning model, which proved that critical thinking was an indispensable part of education. Similarly, Çakır and Cengiz (2016) made a training program activity about classroom questions strategies for teachers in Turkey who asked open or closed questions to different grades at different schools with video recording in their classes. They revealed that the teachers asked more open-ended questions, leading to more student participation, and more dialogue in the classrooms. High dialogicality assisted students to produce positive emotions to boost their studies. Such kind of question also strengthened students' critical thinking capabilities in some degree, which was beneficial to students' long-term development. Besides, there were some people discussing it from viewing the nature of human and human society. Lin, (2016) explored the book Not for Profit: Why Democracy Needs the Humanities by Martha C. Nussbaum to explore serious repercussions of education that had only economic target and overlook humanistic spirits involved, mentioning a country must cultivate the critical thinking ability of its citizens. Students were a mobile class, and a huge influential part of the whole structure of society. Therefore, students with high consciousnesses of fostering democratic perspective towards upcoming issues could become potentially powerful participants in developing one country. 


\section{Chinese students' critical thinking skills}

People have had profound and long discussions on Chinese students' behaviors in critical thinking and its related occasions in school for a long time. Some managed to take a panoramic view of the situation of Chinese students. From the domestic perspective, Zhu, (2015) on China Daily chose own growing story to point out that Chinese educational strategy focused on projecting students the reality and objectivity of the knowledge; However, they failed in guiding students how to think critically why and how it comes like this. The author admitted that her way of thinking has been trapped in an invisible frame. Besides, after a long-term suppressing, students' creativity will be harmed greatly. From the Anglophone people's opinion, Hernández (2016) claimed that although the students in secondary school in China outperforming compared to other global peers in reading, mathematics and science part, Chinese students still carried the image that they were seen as lack critical thinking capabilities. Some people investigated English majors and non-English majors in universities. A recent research study (Pei, Zheng, Zhang, and Liu, 2017) pointed that English majors did not possess strong Critical Thinking Skills (CTS) by evaluating 110 English majors' performance across three grades at two universities in China. Moreover, there was no apparent difference in CTS across the three grades. Meanwhile, Zhou, Jiang and Yao (2014) showed that the learning outcomes of interviewed 224 non-English majors in their English as a Foreign Language (EFL) reading class from a university in China is not satisfactory. Furthermore, they found that both teachers and students have some problems involved, such as attitude and methodology etc.

\section{Teaching critical thinking skills in real classrooms}

Legions of researches also give qualified scenarios for educators or people who desire to study CT issues and find out proper solutions towards them. Some took root in providing suggestions for reformations by analyzing materials. Shang (2018) researches current reforms and developments in higher education in the United States to see the common themes in different contexts of China and the US. It reveals some certain values of the US current suitable for China in developing its Double First Class education. When it comes to the learning of students, Willingham (2008) found that the students are easily focusing on the surface structures, making they lack capabilities into solving the real problems related to what they have learned, which was alsocalled applying deep structure. This outcome also showed one of the reasons that CT was difficult to teach in traditional classroom.

Some practice different ways of teaching to figure out a more proper way in one specific area. Liu and Li (2015) conducted an investigation in eight large mathematics classrooms with 381 students, concluding that there were possibilities for Chinese students to think critically and creatively in traditionally instructed classes. Zhou (2018) aimed to explore the critical thinking ability of college students through English Problem Based Learning (PBL) teaching model among randomly selected English major sophomores from two classes from a second level university in Jiangxi province in China, and the experimental results revealed that compared with traditional teaching, PBL teaching model can improve three English critical thinking temperament level as analysis, openness and fair and significantly improve the two English critical thinking skills of analysis and interpretation. Mehta and Al-Mahrouqi (2015) transferred the CTS into students' writing based on a specific research of 30 English majors at Oman's Sultan Qaboos University through giving contrasts samples of student writing on a given topic at the beginning and the end of a semester-long course on critical reading skills. It showed that we can adjust the turning way in terms of the specific situation to make link between CTS and writing more suitable for students. Lun (2010) studied the outcomes of setting test of 70 students (ethnically Chinese, New Zealand European, and other ethnic identities such as New Zealand Maori and Samoan) in a university in New Zealand. Lun indicates that English language proficiency but not dialectical thinking style explained the difference of behavior in CT between Asian students and New Zealand European students. In other words, the difference in CT tended to be a linguistic issue instead of a cultural issue. Furthermore, Lun concluded that dialectical thinking style may be more beneficial to Asian students but not New Zealand European students to improve CTS. Fuad (2017) conducted a quasi-experimental research of 96 students in three classes at different schools 
through giving them three kinds of learning models to see the degree of improvement in CT. He expounded students exposed to the learning model combined with both Differentiated Science Inquiry (DSI) and mind map could improve their CTS mostly, compared to the other two models (DSI instructional model and conventional model).

\section{Discussion and Recommendation}

\section{Importance of CT needs more attention}

During the reference searching, the author found that studies mainly talking about Chinese high school students' behavior in CT were much fewer than passages about universities students or some papers focusing on one existing subject. Out of the author own observations, lots of the students around lacked a good CT consciousness, for example: They could not put forward logical and dialectical points in a debate; They could not deny one given topic and raise a proper and innovative analysis, and etc.

Pioneer jobs to explore the importance of CT had been done for long years and the premise that people did not know some basic information of CT was false. Actually, in the first part of key findings, what the author attempted to do was to dig more potential meanings of CT out to arouse readers more empathy for setting the CT course in high school in China. The improvements of the depth and utility of discussions about CT in China and their degree of influence projecting on the students boosted like chromosome. People always heard the news of it but indeed couldn't feel that it made a huge difference compared to the past. But there was no doubt that human-beings are making progress with standing on past great intelligence' shoulders.

\section{Paradox of current Chinese CT acquiring}

In recent years, Chinese students behaved well in lots of fields needing high consciousnesses of CT, which is easily seen for people in the world. And it is not a tough work to find the contents about Chinese education ministry and different kinds of civil organizations stress the importance of creativity again and again. On the one hand, high school students who chose the liberal arts will learn the basic Marxism theory including some factors of CT. On the other hand, Students who chose the science would learn more difficult and complex mathematics, accompany physics and other subjects related to figures. However, the consequence is not satisfactory. Chinese students are still undertaking the image of rote students without high CT capabilities. Whether the average level of Chinese students' CT abilities increased to an expected layer was still a question mark.

From the perspectives of the author, the situation was weird for current high school students in China to acquire knowledge of CT. As the author wrote in key findings, the definition of CT sometimes used the Anglophone theories and its assessment was done in terms of them reversely. What Liberal arts students learned about philosophical thinking pattern follow the basic disciplines of Marxism such as "the social being determines their consciousness", against lots of western believes. Moreover, it was appreciative that they learned CT from a philosophical view. But they lacked adequate practice involving specific cases. They still could not break the circle of the scores and the "threat" of Gaokao. When it came to the science students, lots of people agreed science students were good at CT. The author had experienced countless situations like that. It was easily to break this illusion through giving them a heated social case and let them figure out different perspectives towards it. Lacking enough liberal arts qualities, some of them not only could not give a quite comprehensive answer but also usually gave answers far from the humanistic spirits.

Increasing universities in China required students have qualified CT abilities to handle more sophisticated problems. Also, universities in other countries expected Chinese students studying abroad could create more. Having a high level of $\mathrm{CT}$ and becoming more innovative were not a new trend. However, due to the essence of post-graduate education was to build students basic of academic researching and the complex working system in 
Chinese universities did not just serve for the students, students could not acquire enough CT knowledge in universities in China. It meant that students originally having no high CT capabilities would almost stay what they stood after receiving universities' teaching. Students who were regarded as good at CT due to they thought different to the ordinary students, but in essence did not receive a systematical training, would continue to deliver some comment against universal values sometimes. Such a cycle could not foster what universities wanted at the beginning. In addition, students who already had high level of CT (having special training in high school or other camps before) would be restrained by the whole atmosphere if the average level of the schoolmates was far lower than them. Their interest of digging deeply in some fields may be abated. Therefore, more top students transferred themselves into "practical working" in order to earn more fortune, leading the lack of potential academic researchers. Above all was able to be avoided or may at least be avoided a lot.

\section{Reasons for establishing separate CT course in High school}

High school is the most important transition period of Chinese students. There would be fewer related problems if high school had already set that. If they just learned the strategies of passing a test in high scores, it was not only a pity for students themselves but also a tragedy of a nation.

Setting CT course in high school was a way to apart CT skills cultivation of students from the traditional subjects they have got used to learning. The author thought the reasons school did not establish the separate course for CT were to reduce the material expenditure and release students' existing burden from Chinese, mathematics, English and so on. Also, they called for all the subjects should cover the CT factors with some written suggestions. Some students did acquire the essence of CT and learn a lot from the traditional way. They were few and had been learned more. However, improving CT capabilities was like building a stage for further study of all the subjects. With the stage becoming stronger and more colorful, students could see issues in different perspectives and the possibilities of creating more meaningful workings rose. Chinese high school students could not cherish a serious attitude towards learning CT skills or improve CT capabilities if the CT was just an included factor of all kinds of essential subjects directly related to their future lives. They would finally come back scores-oriented studying pattern but not absorb and utilize the essential competence like CT capabilities. Additionally, using a fixed time for CT training not only improved the efficiency of students learning, but also left more constant space for other traditional subjects. Student can practice what they learn in the CT class positively in other subjects. If we separate it from the traditional subjects and also contain its application into all the subjects, it would give larger motivation to students. Moreover, great amount of repetitive homework would make students' mind dull and negative. CT course would be a way for Chinese students to bestir their brains.

\section{Reforming can be taken in Chinese style}

Although China is at its primary stage of socialism, which is still a developing country, it must have the common willing like other developed countries that human beings finally will build a society where all the citizens have equal access to high-quality education. A part of students behaving well in CT was not the expected goal. Making unremitting efforts to boost more and more students' CT capabilities and then helping them gain more achievements due to it, is what the world shall want. No country can be an island into education field. Although China fostered students according to its own values, just like other countries did, there were some values that all the human beings are agreed with. And CT capabilities must be on that list. Developing Chinese students CT was also a behavior to match the international trend.

Setting a CT course is not requiring China to simply follow the western pattern. Chinese education had its own exploring way. It should follow the principles of "Take its essence and discard its dregs" (J, 2018). It can combine its own conditions and make it more suitable such as people transferring CT capabilities cultivation into writing class and so on. Chinese can embody CT teaching into different specific patterns firstly, and then 
gradually setting CT an independent subject. In America, some schools set logic class for high school students. But logic is just a part of CT teaching, which cannot replace the CT. Chinese people can create a more matching way through learning from other countries' practice.

\section{Recommendations}

Such a class can be set twice a week. Teachers should firstly work together to produce a common macro teaching plan with united determination to develop students' CTS. They should at least systematically introduce the facts of CT and help students understand deeply about CT at beginning classes. Then teachers should combine the $\mathrm{CT}$ exercise and other forms together, such as reading materials and giving $\mathrm{CT}$ respond, writing a passage from different perspectives, watching a heated video and delivering a short speech or circling one topic and giving a simple debate, and etc. The education ministry or other policies makers should set related criteria of CT course strictly, for example, publishing unified textbook or macro-plans in the whole nation and add some irregular assessment. Also, there could be a reformation to help this course match the traditional teaching for Chinese students. Scholars should conduct more investigations to prove that including CT course into examinations even in Gaokao is feasible. They can figure out other evaluation ways to both give respond for students' behavior and urge them to learn CT passionately. More specific content of the course should be considered by them. Doubtlessly, they should continue to discuss other proper ways to improve students CT capabilities.

Considering different possibilities to prevent setting separate subject of CT, the author still hope the exercise of it. Maybe it just needs a trying step to see the worth.

\section{Conclusion, Limitation, and Implication for Future research}

Through the review of literature, the three critical questions were answered. First, CT was an indispensable part of education, having huge benefits for Students' studying career and the nation's development. Second, Chinese students still undertook a negative image that they were not good at CT from both domestic and anglophone views, even though they had won applause in fields needing high CTS. Third, various scenarios had offered suggestions to improve CT in classroom, informing a theoretical basic for Chinese education's reformations. In addition, critical analyses and practical implementing are also addressed. For instance, the paradox of current Chinese students to learn CTS could not bring them satisfactory results. Exploring a new way in terms of Chinese own conditions awaited. Establishing a separate CT course may be a worthy try after the author's analysis.

For this current study, it has its limitation in 4 ways. For the methods of data collection, the author uses an allfree searching method to find references due to the limitation of Internet access leading to an outcome containing unbalanced content and inadequate evidences attached. For the amount of data collected, it seemed not enough to present the degree of needing and availability of the CT reformation. Some related primary research's results were local or regional. It cannot mean China, a non-Anglophone country, should have a deeper reception of western theory production. In addition, some aspects involved are not professional as their own fields' specialized people having learned.

For future research, this literature review highlights promising avenues including scholars should survey more specific content in a CT course and so on. Future research is needed to find more support and conduct more researches to prove the feasibility of establishing a CT course in high school.

\section{Acknowledgement}

When completing this literature review, as my first paper, I received different persons' guides, comforts and suggestions. I must express my gratitude towards my mother Guiru Wang, who unconditionally supported me 
when I proposed to produce my own paper. Also, it was Miss Gao from Pittsburg University who leaded me into the academic circle, teaching me how to write a literature review. Besides, my academic group members, Becky, Eira and Zoey, assisted me out of imagination, such as grammar checking, schedule management, and so forth. Moreover, my dear friends in university in China, Ru Dai, Jiayu Zhao, Feifei Xiao, Zongxian Li and Qiuyan Wang, gave many useful suggestions when I prepared the mock paper defense. Thank you so much!

\section{References}

Çakır, H., \& Cengiz, Ö. (2016). The use of open ended versus closed ended questions in Turkish classrooms. Open Journal of Modern Linguistics, 6(02), 60.

Cheng, M. H. M., \& Wan, Z. H. (2017). Exploring the effects of classroom learning environment on critical thinking skills and disposition: A study of Hong Kong 12th graders in Liberal Studies. Thinking Skills and Creativity, 24, 152-163.

Daniel, M. F., Belghiti, K., \& Auriac-Slusarczyk, E. (2017). Philosophy for Children and the Incidence of Teachers' Questions on the Mobilization of Dialogical Critical Thinking in Pupils. Creative Education, 8(06), 870-892.

Dong, Y. (2013). 批判性思维三大误解辨析. 高等教育研究, (11), 64-70.

Fuad, N. M., Zubaidah, S., Mahanal, S., \& Suarsini, E. (2017). Improving Junior High Schools' Critical Thinking Skills Based on Test Three Different Models of Learning.International. Journal of Instruction, 10(1), 101-116.

Hongjuan, S. (2018). How First-Class Undergraduate Education Reform in the United States Can Inform the Development of Double First Class Education in China. Chinese Education \& Society, 51(4), 282-293.

The Sate Council. (2017). Report of the State Council on 2017. Beijing: The Sate Council.

Lin, J. (2016). What Is Education For? A Discussion of Nussbaum's Not for Profit: Why Democracy Needs the Humanities. Education and Urban Society, 48(8), 767-779.

Liu, Z. K., He, J., \& Li, B. (2015). Critical and creative thinking as learning processes at top-ranking Chinese middle schools: possibilities and required improvements. High Ability Studies, 26(1), 139-152.

Lu, S., \& Singh, M. (2017). Debating the Capabilities of "Chinese Students" for Thinking Critically in Anglophone Universities. Education Sciences, 7(1), 22.

Lun, V. M. C., Fischer, R., \& Ward, C. (2010). Exploring cultural differences in critical thinking: Is it about my thinking style or the language I speak? Learning and Individual differences, 20(6), 604-616.

Mehta, S. R., \& Al-Mahrooqi, R. (2015). Can thinking be taught? Linking critical thinking and writing in an EFL context. RELC journal, 46(1), 23-36.

MirshahJafari, K. A. E., Sharif, M., Asgari, M., \& Omidi, M. The impact of guided inquiry methods of teaching on the critical thinking of high school students.

Pei, Z., Zheng, C., Zhang, M., \& Liu, F. (2017). Critical Thinking and Argumentative Writing: Inspecting the Association among EFL Learners in China. English Language Teaching, 10(10), 31.

Tapung, M., Maryani, E., \& Supriatna, N. (2018). Improving Students' Critical Thinking Skills in Controlling Social Problems through the Development of the Emancipatory Learning Model for Junior High School Social Studies in Manggarai. Journal of Social Studies Education Research, 9(3), 162-176.

Willingham, D. T. (2008). Critical thinking: Why is it so hard to teach? Arts Education Policy Review, 109(4), 21-32.

Xi, J. (2016). Speech at the Fifth Plenary Session of the Eighteenth CPC. Central Committee (Extract). Qiushi, (1674-7569), 3-15.

Zhou, J., Jiang, Y., \& Yao, Y. (2015). The Investigation on Critical Thinking Ability in EFL Reading Class. English Language Teaching, 8(1), 83-94.

Zhou, Z. (2018). An Empirical Study on the Influence of PBL Teaching Model on College Students' Critical Thinking Ability. English Language Teaching, 11(4), 15-20.

Zhu, J. (2015). Critical thinking, an ability Chinese students need. China Daily, 9, 2015-06. 